\title{
Optimasi Penempatan Group Tower Crane pada Proyek Pembangunan My Tower Surabaya
}

\author{
Ahmad Puguh Septiawan dan Cahyono Bintang Nurcahyo \\ Teknik Sipil, Fakultas Teknik Sipil dan Perencanaan, Institut Teknologi Sepuluh Nopember (ITS) \\ Jl. Arief Rahman Hakim, Surabaya 60111 Indonesia \\ e-mail: bintang@ce.its.ac.id
}

\begin{abstract}
Abstrak-Tower Crane adalah alat yang digunakan untuk mengangkut material secara vertikal dan horizontal ke suatu tempat yang tinggi pada ruang gerak yang terbatas. Pada saat pemilihan tower crane sebagai alat pengangkatan yang akan digunakan, ada beberapa pertimbangan yang perlu diperhatikan, yaitu kondisi lapangan yang tidak luas, ketinggian tidak terjangkau oleh alat lain, dan pergerakan alat tidak perlu. Pertimbangan ini harus direncanakan sebelum proyek dimulai karena tower crane diletakkan di tempat yang tetap selama proyek berlangsung, tower crane harus dapat memenuhi kebutuhan pemindahan material sesuai dengan daya jangkau yang ditetapkan.

Pada konstruksi proyek yang besar, seperti pada proyek My Tower Surabaya, tower crane bekerja lebih ekstra terutama ketika tower crane tunggal tidak bisa melayani keseluruhan pekerjaan pengangkatan dari semua titik persediaan dan titik kebutuhan, maka perlu digunakan lebih dari satu tower crane, atau biasa disebut group tower crane. Dengan adanya lebih dari satu tower crane bukan berarti semua masalah pekerjaan pengangkatan bisa teratasi, karena pada proyek yang memiliki lahan yang kurang luas, semakin banyak tower crane menyebabkan sering terjadinya tabrakan ataupun tumpang tindih antar tower crane. Dari permasalahan tersebut perlu adanya pengoptimalan lokasi untuk group tower crane. Lokasi yang optimal adalah lokasi yang memiliki konflik indeks dan keseimbangan beban kerja antar tower crane terkecil. Karena tower crane yang digunakan lebih dari satu maka penempatan tower crane harus sesuai pada titik yang optimal.

Dalam perhitungan untuk mendapatkan hasil yang optimal pada penempatan tower crane direncanakan menggunakan 3 skenario. Dari hasil penelitian ini dapat disimpulkan bahwa skenario 3 adalah skenario yang paling optimal dibandingkan skenario 1 dan skenario 2, karena skenario 3 memiliki nilai konflik indeks (NC) terkecil yaitu 6 dan keseimbangan beban kerja ( $\sigma$ ) terkecil yaitu 2,249 jam serta dengan biaya operasional sebesar Rp 1.256.778.497, -.
\end{abstract}

Kata Kunci-Keseimbangan Beban Kerja, Konflik Indeks, Tower Crane, Optimasi Lokasi.

\section{PENDAHULUAN}

A. Latar Belakang

KEBUTUHAN masyarakat akan hunian mewah yang Kditunjang dengan fasilitas modern di Kota Surabaya semakin meningkat. Hal ini ditandai dengan semakin banyaknya pembangunan apartemen dan hotel yang menawarkan berbagai macam fasilitas. Pada pembangunan sebuah gedung bertingkat tinggi, diperlukan perencanaan yang matang agar tercapai hasil yang diharapkan dan juga bisa meminimalisir terjadinya masalah yang mengakibatkan kerugian. Sebuah keputusan yang buruk cenderung memiliki efek negatif yang signifikan, yang akan menyebabkan biaya tambahan dan kemungkinan penundaan [1]. Perencanaan utama yang nantinya digunakan sebagai dasar pelaksanaan konstruksi adalah metode pelaksanaan konstruksi. Di dalam metode ini terdapat urutanurutan pekerjaan yang berkaitan dengan proses pekerjaan konstruksi, seperti pekerjaan bekisting, pembesian, pengecoran, maupun pekerjaan lainnya. Metode pelaksanaan konstruksi juga mengatur pelaksanaan penggunaan alat berat. Alat-alat berat yang sering dipakai pada pekerjaan konstruksi gedung bertingkat tinggi adalah tower crane, mobile crane, excavator, dump truck, dan sebagainya.

Tower Crane adalah alat yang digunakan untuk mengangkut material secara vertikal dan horizontal ke suatu tempat yang tinggi pada ruang gerak yang terbatas [2]. Pada saat pemilihan tower crane sebagai alat pengangkatan yang akan digunakan, ada beberapa pertimbangan yang perlu diperhatikan, yaitu kondisi lapangan yang tidak luas, ketinggian tidak terjangkau oleh alat lain, dan pergerakan alat tidak perlu. Pertimbangan ini harus direncanakan sebelum proyek dimulai karena tower crane diletakkan di tempat yang tetap selama proyek berlangsung, tower crane harus dapat memenuhi kebutuhan pemindahan material sesuai dengan daya jangkau yang ditetapkan.

Pada konstruksi proyek yang besar, seperti pada proyek My Tower Surabaya, tower crane bekerja lebih ekstra terutama ketika tower crane tunggal tidak bisa melayani keseluruhan pekerjaan pengangkatan dari semua titik persediaan dan titik kebutuhan, maka perlu digunakan lebih dari satu tower crane, atau biasa disebut group tower crane. Dengan adanya lebih dari satu tower crane bukan berarti semua masalah pekerjaan pengangkatan bisa teratasi, karena pada proyek yang memiliki lahan yang kurang luas, semakin banyak tower crane menyebabkan sering terjadinya tabrakan ataupun tumpang tindih antar tower crane. Tabrakan dan tumpang tindih tersebut bahkan dapat terjadi apabila jib tower crane bekerja pada level yang berbeda.

\section{B. Rumusan Masalah}

Permasalahan yang akan dibahas pada penelitian ini adalah:

1. Dimanakah lokasi group tower crane yang memiliki nilai konflik indeks dan keseimbangan beban kerja antar tower crane terkecil pada proyek pembangunan My Tower Surabaya

2. Berapa biaya operasional yang dibutuhkan untuk group tower crane pada proyek pembangunan My Tower Surabaya 


\section{Tujuan}

Adapun tujuan yang hendak dicapai pada penelitian ini yaitu:

1. Mengetahui titik lokasi group tower crane yang memiliki konflik indeks dan keseimbangan beban kerja antar tower crane paling kecil.

2. Mengetahui biaya operasional yang dibutuhkan untuk group tower crane.

\section{Batasan Masalah}

Dalam penelitian ini permasalahan yang dibahas akan dibatasi, yaitu:

1. Penelitian dilakukan pada proyek pembangunan My Tower Surabaya, yang berada di Jalan Raya Rungkut Industri No.1 Surabaya

2. Optimasi yang dilakukan adalah optimasi penempatan group tower crane dengan memperhatikan konflik indeks dan keseimbangan beban kerja antar tower crane terkecil

3. Jumlah tower crane telah ditentukan, yaitu 2 buah

4. Spesifikasi tower crane telah ditentukan

5. Analisis biaya yang diperhitungkan meliputi biaya sewa alat, bahan bakar, operator, dan alat penunjang tower crane.

\section{METODOLOGI}

\section{A. Analisis Teknis}

Dalam analisis group tower crane, hasil penempatan supply area dari single tower crane digunakan untuk memulai proses analisis. Dimana antara supply area dan demand area membentuk suatu task yang selanjutnya akan dianalisis kedekatannya, sehingga membentuk suatu group task. Kedekatan suatu task diukur dari overlapping area. Semakin besar overlapping area maka semakin dekat antar task.

\section{B. Variabel Penelitian}

Untuk mengetahui lokasi group tower crane yang memiliki konflik indeks dan keseimbangan beban kerja antar tower crane paling kecil, maka ditentukan beberapa variabel dan analisis perhitungan dalam mengolah data penelitian [3]. Variabel dan analisis perhitungan tersebut dapat dilihat pada tabel 1 berikut,

Tabel 1

Variabel dan Analisis Perhitungan [4]

\begin{tabular}{|c|c|c|}
\hline No & Variabel & Analisis Perhitungan \\
\hline 1 & $\begin{array}{l}\text { Waktu } \\
\text { pengangkutan } \\
\text { pengait } \text { tower } \\
\text { crane } \text { ke-i }\end{array}$ & $\begin{array}{l}\mathrm{T}_{\mathrm{i}}=\sum_{\mathrm{j}=1}^{\mathrm{J}} \delta_{\mathrm{ij}} \cdot \mathrm{Q}_{\mathrm{j} .}\left(\mathrm{t} 1_{\mathrm{ij}}+\mathrm{t} 2_{\mathrm{ij}}+\mathrm{t} 3_{\mathrm{ij}}+\mathrm{t} 4_{\mathrm{ij}}\right) \\
\text { Dimana: } \\
\mathrm{T}_{\mathrm{i}}=\text { waktu pengangkutan pengait crane ke- } \mathrm{i} \\
\delta_{\mathrm{ij}}=\text { variabel binary } \\
\mathrm{Q}_{\mathrm{j}}=\text { jumlah angkatan untuk pekerjaan } \mathrm{j} \\
\mathrm{t} 1_{\mathrm{ij}}=\text { waktu perjalanan pengait dengan beban } \\
\mathrm{t} 2_{\mathrm{ij}}=\text { waktu perjalanan pengait tanpa beban } \\
\mathrm{t} 3_{\mathrm{ij}}=\text { waktu jeda rata-rata pengangkatan } \\
\mathrm{t} 4_{\mathrm{ij}}=\text { waktu jeda rata-rata pembongkaran }\end{array}$ \\
\hline 2 & $\begin{array}{l}\text { Waktu rata-rata } \\
\text { pengang- katan } \\
\text { dari semua } \\
\text { tower crane }\end{array}$ & $\begin{array}{l}\overline{\mathrm{T}}=1 / \mathrm{I} \cdot \sum_{\mathrm{i}}^{\mathrm{I}} \mathrm{T}_{\mathrm{i}} \\
\text { Dimana: } \\
\overline{\mathrm{T}}=\text { waktu rata-rata pengangkutan dari semua } \\
\text { crane } \\
\mathrm{T}_{\mathrm{i}}=\text { waktu pengangkutan pengait crane } \text { ke- } \mathrm{i}\end{array}$ \\
\hline
\end{tabular}
beban kerja pada masing-masing waktu untuk setiap tower crane

$4 \quad$ Konflik antar tower crane
3 Keseimbangan pengangkutan

$\sigma=\sqrt{\sum_{\mathrm{i}}^{\mathrm{I}} \frac{\left(\overline{\mathrm{T}}-\mathrm{T}_{\mathrm{i}}\right)^{2}}{1}}$

Dimana:

$\sigma=$ kriteria penentuan pekerjaan

$\overline{\mathrm{T}}=$ crane

$\mathrm{T}_{\mathrm{i}}$ = waktu pengangkutan pengait crane ke- $\mathrm{i}$

$\mathrm{NC}_{\mathrm{ik}}=\sum_{\mathrm{l}=1}^{\mathrm{L}} \sum_{\mathrm{j}=1}^{\mathrm{J}} \mathrm{n}_{\mathrm{ij}, \mathrm{kl}}\left(\mathrm{Q}_{\mathrm{ij}}+\mathrm{Q}_{\mathrm{kl}}\right)$

Dimana:

$\mathrm{n}_{\mathrm{ij}, \mathrm{kl}} \quad=$ jumlah perpotongan antar segitiga

$\mathrm{Q}_{\mathrm{ij}}=$ jumlah angkatan pekerjaan $\mathrm{j}$

$\mathrm{Q}_{\mathrm{kl}}=$ jumlah angkatan pekerjaan 1

\section{Skenario Permodelan}

Untuk mengetahui alur dalam mengerjakan penelitian ini maka dapat dilihat pada gambar 2 berikut ini:

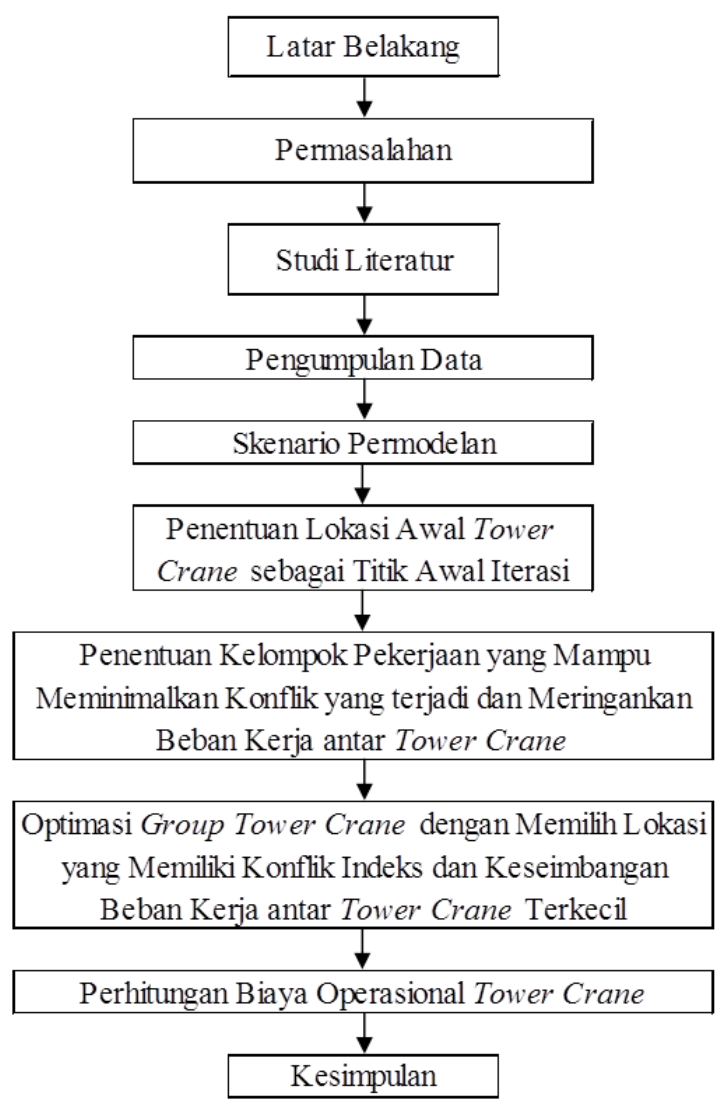

Gambar 1. Bagan Alir Penelitian

Ada 3 skenario yang dilakukan untuk memperoleh titik optimal. Masing-masing skenario memiliki perbedaan seperti di bawah ini:

1. Skenario 1

Dalam skenario ini dicari titik optimal tower crane sesuai dengan data eksisting di lapangan. Radius tower crane adalah $60 \mathrm{~m}$. 


\section{Skenario 2}

Dalam skenario ini dicari titik optimal tower crane pada kondisi titik supply yang telah dimodifikasi lokasi penempatan dan jumlahnya, sedangkan untuk koordinat dan radius tower crane yang digunakan sama seperti data pada skenario 1 .

\section{Skenario 3}

Dalam skenario ini dicari titik optimal tower crane pada kondisi titik supply dan tower crane yang telah dimodifikasi penempatannya serta radius diperkecil dari skenario 1 . Untuk tower crane 1 dengan radius $50 \mathrm{~m}$ dan untuk tower crane 2 dengan radius $55 \mathrm{~m}$.

\section{ANALISIS PERHITUNGAN}

\section{A. Menentukan Kelompok Pekerjaan untuk Setiap Tower Crane}

Pada setiap pekerjaan yang dapat diakses oleh tower crane diberi nilai 1 dan untuk pekerjaan yang tidak dapat diakses diberi nilai 0 . Apabila ada pekerjaan yang memiliki nilai 1 pada TC 1 dan TC 2 maka pekerjaan tersebut mengalami overlappping. Kemampuan aksesibilitas dari masing-masing tower crane tersebut dapat dilihat pada tabel 2 berikut ini:

Tabel 2

Matriks Aksesibilitas TC 1 dan TC

\begin{tabular}{|c|c|c|c|c|c|c|c|c|c|c|}
\hline Task & 1 & 2 & 3 & 4 & 5 & 6 & 7 & $\ldots$ & 159 & 160 \\
\hline TC1 & 0 & 0 & 0 & 0 & 0 & 0 & 0 & $\ldots$ & 1 & 1 \\
\hline TC2 & 1 & 1 & 1 & 1 & 1 & 1 & 1 & $\ldots$ & 1 & 0 \\
\hline
\end{tabular}

\begin{tabular}{|c|c|c|c|c|c|c|c|c|c|c|}
\hline Task & 161 & 162 & 163 & 164 & 165 & 166 & 167 & $\ldots$ & 333 & 334 \\
\hline
\end{tabular}

\begin{tabular}{|c|c|c|c|c|c|c|c|c|c|c|}
\hline TC1 & 1 & 1 & 1 & 1 & 1 & 1 & 1 & $\ldots$ & 1 & 1 \\
\hline TC2 & 1 & 1 & 1 & 0 & 1 & 1 & 0 & $\ldots$ & 0 & 0 \\
\hline
\end{tabular}

B. Menghitung Keseimbangan Beban Kerja dan Konflik Indeks

- Perhitungan Keseimbangan Beban Kerja

Untuk perhitungan standart deviasi $(\sigma)$ keseimbangan beban kerja pada masing-masing waktu pengangkutan untuk setiap crane menggunakan :

$\sigma=\sqrt{\sum_{\mathrm{i}}^{\mathbb{I}} \frac{\left(\mathrm{T}-\mathrm{T}_{\mathrm{i}}\right)^{2}}{\mathrm{I}}}$

$=\sigma\left(\delta_{11}, \delta_{12, \ldots .}, \delta_{21}, \delta_{22}, \ldots . \delta_{\mathrm{ij},}, \ldots, \delta_{\mathrm{IJ}}\right)$

dengan keterangan :

$\sigma=$ Kriteria penentuan pekerjaan.

$\overline{\mathrm{T}}=$ Waktu rata-rata pengangkutan dari semua crane

$\mathrm{T}_{\mathrm{i}}=$ waktu pengangkutan pengait crane ke-i.

Ti merupakan waktu pengangkutan pengait Crane ke $\mathrm{i}$ :

$\mathrm{T}_{\mathrm{i}}=\sum_{\mathrm{j}=1}^{\mathrm{J}} \delta_{\mathrm{ij}} \cdot \mathrm{Q}_{\mathrm{j}} \cdot\left(\mathrm{t} 1_{\mathrm{ij}}+\mathrm{t} 2_{\mathrm{ij}}+\mathrm{t} 3_{\mathrm{ij}}+\mathrm{t} 4_{\mathrm{ij}}\right)$

dengan keterangan :

$\mathrm{Ti}=$ waktu pengangkutan pengait crane ke-i.

$\delta \mathrm{ij}=$ variabel binary.

$\mathrm{Qj}=$ Jumlah angkatan untuk pekerjaan $\mathrm{j}$.

t1ij = Waktu perjalanan pengait dengan beban.

$\mathrm{t} 2 \mathrm{ij}=$ Waktu perjalanan pengait tanpa beban.

t3ij = Waktu jeda rata-rata pengangkatan.

$\mathrm{t} 4 \mathrm{ij}=$ Waktu jeda rata-rata pembongkaran.

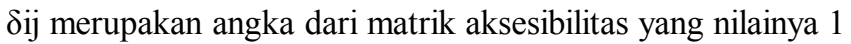
atau 0 , sedangkan $\mathrm{Q}$ adalah frekuensi distribusi dan $\left(\mathrm{t}_{\mathrm{ij}}+\mathrm{t} \mathrm{t}_{\mathrm{ij}}+\right.$ $\mathrm{t} 3_{\mathrm{ij}}+\mathrm{t} 4_{\mathrm{ij}}$ ) merupakan total waktu yang diperlukan untuk mengangkat material dari titik supply ke titik demand dengan lokasi tower crane yang telah ditentukan sebelumnya.

Menghitung waktu perjalanan pengait pekerjaan dari titik supply ke titik demand

$\mathrm{T}=\max (\mathrm{Th}, \mathrm{Tv})+\beta \min (\mathrm{Th}, \mathrm{Tv})$

$\mathrm{Tv}=\left(\mathrm{ZD}_{\mathrm{j}}-\mathrm{ZS}_{\mathrm{j}}\right) / \mathrm{Vv}$

$\mathrm{Th}=\max (\mathrm{Ta}, \mathrm{T} \omega)+\alpha \min (\mathrm{Ta}, \mathrm{T} \omega)$

$\rho\left(D_{j}\right)=\sqrt{\left(X_{j}-x\right)^{2}+\left(Y D_{j}-y\right)^{2}}$

$\rho\left(S_{j}\right)=\sqrt{\frac{\left(X S_{j}-x\right)^{2}+\left(Y S_{j}-y\right)^{2}}{\left(X D_{j}-X S_{j}\right)^{2}+\left(Y D j-Y S_{j}\right)^{2}}}$

$l_{\mathrm{j}} \quad=\sqrt{\left(\mathrm{XD}_{\mathrm{j}}-\mathrm{XS}_{\mathrm{j}}\right)^{2}+\left(\mathrm{YD}_{\mathrm{j}}-\mathrm{YS}_{\mathrm{j}}\right)^{2}}$

Waktu pergerakan radial trolley

$\mathrm{T}_{\mathrm{a}}=\left|\frac{\rho(D j)-\rho\left(S_{j}\right)}{V_{\mathrm{a}}}\right| ; \mathrm{T} \omega=\frac{1}{\omega} \cdot \operatorname{Arc} \cos \left(\frac{j_{j}^{2}-\rho\left(D_{j}\right)^{2}-\rho\left(S_{j}\right)^{2}}{2 \bullet \rho\left(D_{j}\right) \cdot \rho\left(S_{j}\right)}\right) ;(0 \leq \operatorname{Arc}$ $\cos (\theta) \leq \pi)$

\section{Dimana}

Th = Waktu perjalanan horizontal pengait

$\mathrm{Tv}=$ Waktu perjalanan vertikal pengait

$\mathrm{Ta}=$ Waktu pergerakan radial trolley

$\mathrm{T} \omega=$ Waktu pergerakan tangensial trolley

$\alpha=$ Derajat koordinasi pergerakan pengait dalam arah radial dan tangensial pada bidang horizontal; (antara 0 sd 1)

$\beta=$ Derajat koordinasi pergerakan pengait dalam arah radial dan tangensial pada bidang vertikal dan horisontal; (antara 0 sd 1)

Setelah dilakukan perhitungan waktu dan keseimbangan beban kerja, maka hasil perhitungan disajikan dalam tabel 3 berikut ini:

Tabel 3

Rekapitulasi Perhitungan Waktu Angkut dan Keseimbangan Beban Kerja

\begin{tabular}{|c|c|c|c|c|}
\hline \multirow{2}{*}{ Lantai } & \multicolumn{3}{|c|}{ Waktu (jam) } & \multirow{2}{*}{$\delta$ (jam) } \\
\hline & TC1 & $\mathrm{TC} 2$ & Total & \\
\hline 1 & 30.217 & 23.95 & 54.167 & 3.133 \\
\hline 2 & 30.69 & 24.322 & 55.012 & 3.184 \\
\hline 3 & 31.212 & 24.733 & 55.945 & 3.239 \\
\hline$\ldots$ & $\ldots$ & $\ldots$ & $\ldots$ & .. \\
\hline 21 & 24.786 & 18.353 & 43.139 & 3.216 \\
\hline \multicolumn{3}{|c|}{ Jumlah } & 924.464 & 64.241 \\
\hline \multicolumn{4}{|c|}{ Rata-rata } & 3.059 \\
\hline
\end{tabular}

- Perhitungan NC menggunakan rumus:

$\mathrm{NC}_{\mathrm{ik}}=\sum_{\mathrm{l}=1}^{\mathrm{L}} \sum_{\mathrm{j}=1}^{\mathrm{J}} \mathrm{n}_{\mathrm{ij}, \mathrm{kl}}\left(\mathrm{Q}_{\mathrm{ij}}+\mathrm{Q}_{\mathrm{kl}}\right)$

Qij merupakan frekuensi angkatan pekerjaan $\mathrm{j}$ oleh tower crane i, sedangkan Qkl merupakan frekuensi angkatan pekerjaan 1 oleh tower crane $\mathrm{k}$ dan nij, $\mathrm{kl}$ adalah jumlah perpotongan atau konflik antara pekerjaan $\mathrm{j}$ oleh TCi dengan pekerjaan 1 oleh TCk. Pada Penelitian ini tower crane yang mengalami konflik adalah TC 1 dan TC 2, maka NC $=\mathrm{NC} 12$. 
Contoh konflik antar pekerjaan dapat dilihat pada gambar 3.1 yang terjadi pada task 215 oleh TC 1 dan task 133 oleh TC 2.

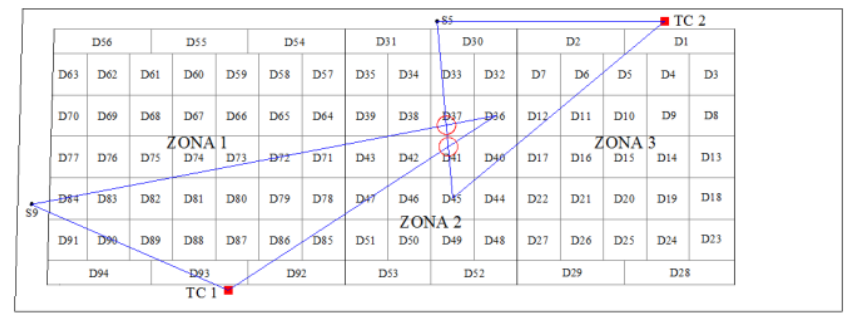

Gambar 2. Perpotongan antar Task dari masing-masing Tower Crane

Dari gambar 2 di atas jumlah perpotongan (n) yaitu 2 titik. Sedangkan frekuensi angkatan pekerjaan 215 oleh TC 1 sebanyak 1 kali dan frekuensi angkatan pekerjaan 133 oleh TC 2 sebanyak 1 kali. Sehingga besarnya nilai konflik yang terjadi adalah $\mathrm{n} \times(\mathrm{Qi}+\mathrm{Qj})=2 \times(1+1)=4$.

Selanjutnya semua pasangan pekerjaan dihitung konflik indeksnya dengan cara yang sama kemudian dijumlahkan semuanya

\section{Iterasi}

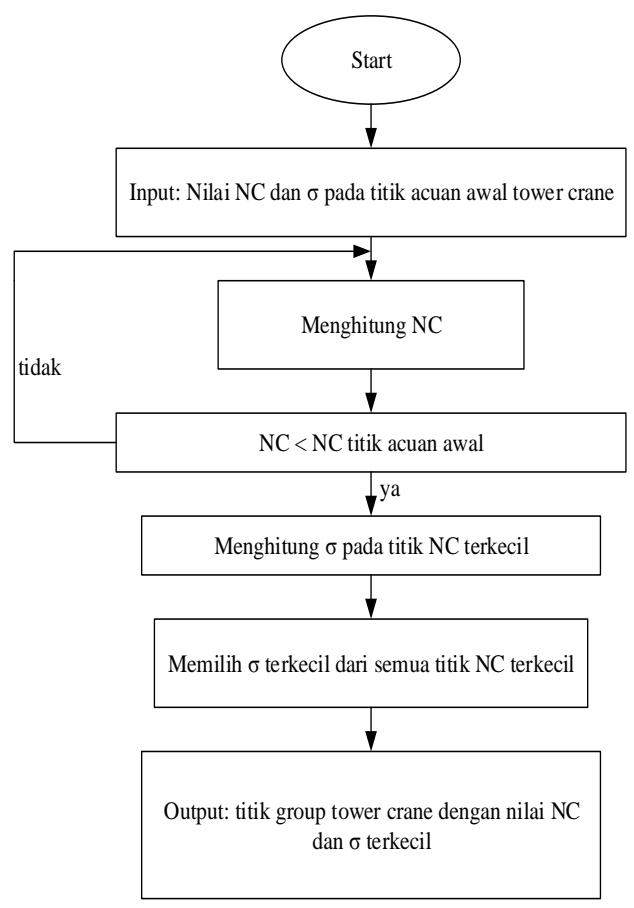

Gambar 3. Flowchart Penentuan Nilai NC dan $\sigma$ pada Group Tower Crane

Proses Iterasi dilakukan untuk mendapatkan dua titik sampel yang memiliki nilai $\mathrm{NC}$ dan keseimbangan beban kerja yang paling kecil dari semua titik sampel yang ada.

Gambar 4 di bawah merupakan titik sampel yang berada dalam feasible task area pada area distribusi TC1 dan TC2. Area TC1 adalah kotak warna hitam putih sebelah kiri sedangkan Area TC2 adalah warna hitam dan putih sebelah kanan. Setiap kotak memiliki dimensi yang sama yaitu $2 \mathrm{~m}$ x 2 $\mathrm{m}$ karena disesuaikan dengan dimensi tower crane yang dipakai. Terdapat 34 titik pada Area TC1 dan 4 titik pada Area
TC2, sehingga jumlah proses iterasi terhadap titik sampel adalah 136 titik.

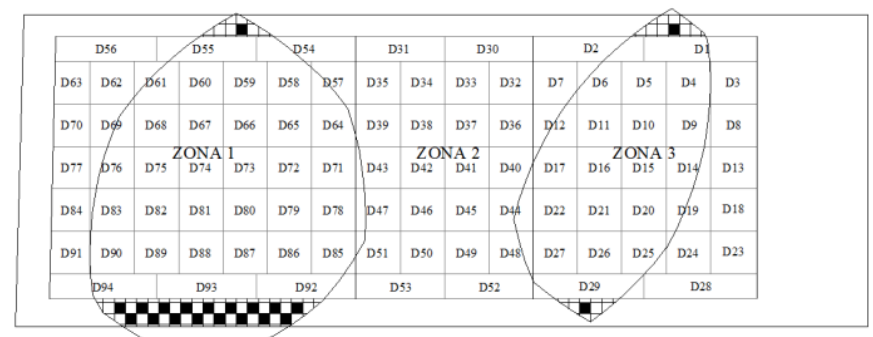

Gambar 4. Feasible Task Area Setelah Iterasi

Setelah dilakukan iterasi maka didapatkan hasil seperti pada tabel 4 berikut:

Tabel 4.

Rekapitulasi Perhitungan Sebelum dan Sesudah Iterasi

\begin{tabular}{|c|c|c|}
\hline & Titik Awal & Setelah Iterasi \\
\hline TC1 & $(40 ; 4)$ & $(19 ; 4)$ \\
\hline TC2 & $(121 ; 54)$ & $(121 ; 54)$ \\
\hline$\sigma$ & 3.059 & 3.202 \\
\hline NC & 1615 & 36 \\
\hline
\end{tabular}

D. Perhitungan Biaya Operasional Tower Crane

Berikut adalah aspek-aspek yang perlu diperhitungkan dalam pengoperasian tower crane:

1. Biaya Mobilisasi dan Demobilisasi

2. Sewa Tower Crane

3. Biaya Erection dan Dismantling

4. Biaya Operator

5. Biaya Listrik

6. Harga bahan bakar

Tabel 5.

Rekapitulasi Biaya Operasional Tower Crane

\begin{tabular}{|c|c|c|c|c|c|c|c|}
\hline NO & ITEM PEKERJAAN & JUMLAH & VOLUME & SATUAN & $\mathrm{SA}^{\prime}$ & $\begin{array}{l}\text { IARGA } \\
\text { UAN (Rp) }\end{array}$ & TOTAL (Rp) \\
\hline 1 & Mob \& Demob & 2 & 1 & Ls & $\mathrm{Rp}$ & $90,000,000$ & Rp $180,000,000$ \\
\hline 2 & Sewa Alat & 2 & 931 & Jam & $\mathrm{Rp}$ & 400,000 & $\operatorname{Rp} 744,800,000$ \\
\hline 3 & Erection \& Dismantling & 2 & 1 & Ls & $\mathrm{Rp}$ & $80,000,000$ & Rp $160,000,000$ \\
\hline 4 & Operator & 2 & 931 & Jam & $\mathrm{Rp}$ & 32,500 & Rp $\quad 60,515,000$ \\
\hline 5 & Listrik & 2 & 931 & Jam & $\mathrm{Rp}$ & 127,979 & Rp 238,297,587 \\
\hline 6 & Bahan Bakar & 2 & 400 & Liter & $\mathrm{Rp}$ & 8,200 & $6,560,000$ \\
\hline \multicolumn{7}{|c|}{ TOTAL } & Rp1,390,172,587 \\
\hline
\end{tabular}

\section{KESIMPULAN DAN SARAN}

\section{A. KESIMPULAN}

Dari hasil penelitian ini dapat disimpulkan bahwa skenario 3 adalah skenario yang paling optimal dibandingkan skenario 1 dan skenario 2, karena skenario 3 memiliki nilai konflik indeks (NC) terkecil yaitu 6 dan keseimbangan beban kerja $(\sigma)$ terkecil yaitu 2,249 jam serta dengan biaya operasional sebesar Rp 1.256.778.497, - .

\section{B. SARAN}

Untuk menyempurnakan penelitian ini pada penelitian selanjutnya maka disarankan untuk menambahkan skenario 
dalam mencari lokasi yang optimal untuk tower crane agar pencarian titik yang optimal bisa lebih maksimal.

\section{DAFTAR PUSTAKA}

[1] Sebt, M. H, Karan, E. P, Delavar. M. R. (2008). Potential Application of GIS to Layout of Construction Temporary Facilities. International Journal of Civil Engineering, Vol.6, No.4, December 2008.

[2] Rostiyanti, Susy Fatena (2008). Alat Berat untuk Proyek Konstruksi. Rineka Cipta, Jakarta.

[3] Rahman, Sofyan (2012). Optimasi Lokasi Untuk Group Tower Crane Pada Proyek Apartemen Guna Wangsa Surabaya. Penelitian, Institut Teknologi Sepuluh Nopember

[4] Tam and Arthur W.T. Leung. (2008). Genetic Algorithm Modeling Aided with 3D Visualization in Optimizing Construction Site Fasility Layout International. Department of Building \& Construction and Division of Building Science and Technology, City University of Hong Kong. 